DOCTRINA

\title{
Las sanciones de Naciones Unidas y su rol político en el conflicto nuclear norcoreano
}

\author{
UN Sanctions and its political role in the North Korean nuclear conflict
}

\author{
María Cecilia Añaños Meza iD \\ Abogada independiente
}

RESUMEN Las sanciones internacionales, instrumentos políticos al servicio de los Estados y organizaciones internacionales como Naciones Unidas están gozando actualmente de gran coyuntura en la práctica internacional. Han sido empleadas en numerosas ocasiones y en diversas formas contra los sancionados, como en el caso norcoreano. La República Popular Democrática de Corea (RPDC) es objeto de unas de las sanciones internacionales más extensas, duras y duraderas que se hayan impuesto a un Estado desde el fin de la Segunda Guerra Mundial. Ellas obedecen en primer orden a la política occidental de persecución enérgica de la proliferación de armas nucleares y armas de destrucción masiva, o política de «contraproliferación». Sin embargo, ellas también enfrentan serios problemas de justificabilidad, que han de ser tratados aquí teniendo presente el amplio conflicto político vinculado necesariamente a ellas. Se trata de un estudio crítico a la perspectiva occidentalista con anotaciones sobre el rol de las sanciones de Naciones Unidas en el conflicto nuclear norcoreano-estadounidense.

PALABRAS CLAVE Sanciones de Naciones Unidas, sanciones económicas, sanciones selectivas, conflicto nuclear, Corea del Norte, no proliferación.

ABSTRACT International sanctions, political instruments at the service of states and international organisations like United Nations enjoy currently high significance in international practice. They have been used in large cases and in different forms against sanctioned subjects like North Korea. The Democratic People's Republic of Korea (DPRK) is target of one of the most extensive, severe and enduring sanctions ever imposed on a State since the end of World War II. They are primarily carried by a western policy of active pursue of nuclear weapons and WMD proliferation, or "counter-proliferation" policy. However, they face serious problems of justifiability which will be dealt here without losing sight of the broad political conflict linked to them. It is a critical appraisal of the occidentalist perspective with some remarks on the role of UN sanctions in the North Korean-American nuclear conflict. 
KEYWORDS UN sanctions, economic sanctions, selective sanctions, nuclear conflict, North Korea, non-proliferation.

\section{Introducción}

Las sanciones internacionales se han convertido en los últimos años en uno de los instrumentos más importantes en la vida política internacional. Recurren a ellas no solo Estados en sus relaciones internacionales con otros Estados, sino también organizaciones internacionales a varios niveles, como Naciones Unidas a nivel universal, y organizaciones regionales y subregionales en ámbitos más limitados geográficamente. Naciones Unidas se ha valido de ellas con frecuencia para reconducir la conducta de los sancionados; pero los Estados, por su cuenta, las han empleado desde tiempos remotos y las están empleando en el presente de forma vertiginosa y alarmante. Su uso prolífico actual proviene sobre todo de potencias occidentales lideradas por Estados Unidos, y el que se extiendan desde las sanciones a países «rebeldes» como Corea del Norte, Venezuela, Cuba, Irán, Siria y Bielorrusia, pasan por países «rivales» como Rusia, llegan a su punto crítico con las sanciones a China en la llamada «guerra comercial», y terminan en las sanciones económicas «internas» entre las potencias occidentales, es signo de su gran poder como arma de coerción política. Este intrincado complejo de sanciones ejercido de forma vertical, esto es, desde la superpotencia a potencias menores y desde estas a Estados más débiles, es muestra también de que las relaciones internacionales, que aún descansan estructuralmente en un sistema internacional descentralizado y horizontal, están siendo objeto de un fenómeno de verticalización creciente, con las sanciones como instrumentos óptimos que refuerzan este fenómeno, el que va en dirección contraria de las demandas de igualdad y equidad en las relaciones internacionales.

Dentro de este entramado sancionatorio se encuentran las sanciones impuestas a la República Popular Democrática de Corea (RPDC), o simplemente Corea del Norte, por Naciones Unidas desde 2006 y dentro de su política de contraproliferación nuclear, a raíz de las actividades y programa nuclear y de misiles balísticos norcoreanos. Además, enfrenta de forma masiva sanciones unilaterales de los Estados y organizaciones regionales o subregionales igual o más extensas que las de Naciones Unidas. Ambas vías sancionatorias, que representan las medidas más draconianas impuestas a un Estado después de Iraq en los años noventa, le han bloqueado sus relaciones con el exterior, incluyendo su comercio exterior, fuente de su subsistencia, y la han condenado a un estado de ilegalidad y clandestinidad.

El presente trabajo se ocupará de las sanciones colectivas de Naciones Unidas contra Corea del Norte desde una perspectiva de la Periferia o Sur Global. Su foco no se encontrará en el tema de su efectividad, que incluye aspectos de implementación 
y perfeccionamiento con sus problemas de evasión, los cuales son abundantes en la literatura occidental, sino su cuestionamiento bajo aspectos de justificación y en cuanto a su rol político en el conflicto nuclear norcoreano-estadounidense ${ }^{1}$ que está ligado a ellas. Esta perspectiva se basa en la asunción de que los asuntos de efectividad u operacionalidad deben ir por necesidad precedidos del examen de justificación de las sanciones. Para ello será necesario esbozar algunos conceptos sobre las sanciones internacionales.

\section{Las sanciones internacionales}

El fuerte incremento de las sanciones en la vida internacional, acompañado de los proyectos de gobernanza global, han llevado a su desarrollo y perfeccionamiento, sobre todo en las técnicas de creación, implementación y cumplimiento, es decir, a su diversificación, pero también a su complejidad; proceso que no está terminado y que ha dificultado más al derecho internacional público la tarea de aprehender este fenómeno y regularlo debidamente. Se encuentran entonces problemas actuales de confusión, sobre todo en su denominación y concepto, aparte de los problemas sobre su alcance y límites, que ya existían antes de su uso explosivo actual; factores que por otro lado influyen en forma significativa en su carácter controvertido. ${ }^{2}$

En cuanto a su denominación, los Estados en su práctica diaria usan indistintamente el término sanciones para designar cualquier medida restrictiva de un Estado u organizaciones internacionales contra otros Estados o individuos; denominación que ha prevalecido frente a otras como medidas restrictivas, contramedidas, acciones coercitivas, represalias, retorsiones, etcétera. La ciencia política está en capacidad de captar estas y otras formas existentes, el derecho internacional público no. Este solo conoce de un número más reducido de ellas, pero recurre a denominaciones más precisas para asignarles diferentes consecuencias jurídicas, como se verá más adelante. Sin embargo, los intentos de precisar el término sanción, sobre todo por la Comisión de Derecho Internacional de Naciones Unidas, no han dado buenos frutos, por lo que no hay acuerdo hoy en el uso de la denominación sanción, y solo se observan tendencias que reservan este término para las medidas coercitivas de Naciones Uni-

1. El conflicto nuclear norcoreano es en esencia un conflicto político entre Estados Unidos y Corea del Norte, en el que Corea del Sur asume el papel de fiel aliado del primero. Se trata de un conflicto político generado por la intervención, ocupación y control político de fuerzas imperiales (tanto norteamericanas como soviéticas) sobre la península de Corea; aserción esta que se opone a la narrativa occidentalista de que el problema nuclear norcoreano es creado solo por este y que tiene una dimensión universal, lo que afecta así a «la comunidad internacional».

2. «Las sanciones internacionales siguen siendo una herramienta política extremadamente controvertida y poco comprendida» (Little, 2018: xvi), la traducción es mía. 
das a partir de la Carta de la Naciones Unidas, ${ }^{3}$ y usan la palabra contramedidas para las medidas coercitivas de los Estados u organizaciones internacionales por su propia cuenta y fuera del marco de la ONU.

En lo referente a su concepto, la situación es similar. No solo no hay una definición aceptada de sanción, sino que existe cierta confusión sobre su contenido (Pellet y Miron, 2011). En unos casos se la concibe como «una forma de hacer cumplir el derecho», ${ }^{4}$ concepto que tiene el problema de excluir a las sanciones colectivas de Naciones Unidas que no están diseñadas para hacer cumplir el derecho, sino «mantener la paz y seguridad internacionales». Tendencias más modernas que intentan ir al paso de la práctica actual de los Estados y son respaldadas por un buen número de autores contemporáneos, prefieren trabajar con nociones más amplias de sanción, esto es, como «medidas coercitivas que no requieren una previa violación del derecho internacional o previa perjudicación de derechos del sancionador» (Gordon, Smyth y Cornell, 2020: 2), noción que desafloja su carácter legal. No existen en el derecho internacional público sanciones puramente políticas ni puramente legales. Entonces las sanciones internacionales son en primer lugar y ante todo medidas de carácter esencialmente político, o para ser más precisos, un instrumento de coerción ${ }^{5}$ que emplean los Estados en forma individual o colectiva, con la intención de afectar derechos de los sancionados, y a fin de que estos accedan a las exigencias del sancionador. Este concepto abarca tanto las medidas coercitivas colectivas de la ONU como las llevadas a cabo fuera de ella, por Estados en forma individual, dentro de organizaciones regionales o bajo formaciones políticas informales o alianzas; se incluyen aquí también las sanciones contra Estados, individuos, grupos o entidades.

Resaltan dos de las características propias de las sanciones internacionales: la privacidad y la efectividad. En cuanto a la primera, ellas constituyen siempre un medio privado de los Estados para restablecer o imponer intereses o derechos propios o ajenos que se creen violados. Este carácter privado - que existe a falta de un Gobierno mundial - no ha desaparecido con la existencia de las sanciones colectivas de Naciones Unidas, ya que esta organización, aun con su carácter universal y su buen grado de institucionalización, no ha superado la barrera de ser el reflejo de la

3. Pellet y Miron (2011: párr. 8) prefieren reservar el nombre de sanción a medidas que tienen un carácter centralizado e institucionalizado. Asada (2020: 4) igualmente se refiere a sanciones para designar las medidas coercitivas de Naciones Unidas u otra organización. De forma matizada, Ronzitti (2016: 15) limita la palabra sanciones a las medidas económicas o no militares de Naciones Unidas bajo el artículo 41; similar, como medidas del artículo 41 de la Carta, Gordon, Smyth y Cornell (2020: 11).

4. Para Doxey, la sanción legal es una reacción coercitiva contra una violación del derecho (Doxey, 1971: 143).

5. De forma similar, Ronzitti (2016: 1, passim) describe las sanciones como instrumento de la diplomacia coercitiva; también Hafner (2006: 391). 
voluntad de los Estados y de la pugna de poder e intereses en ella, ${ }^{6}$ por lo que carece en realidad de personalidad cualitativamente distinta a la suma de sus miembros $y$, por ende, de «autoridad universal»; ello pese a su reconocimiento jurídico como tal por el derecho internacional público, la doctrina mayoritaria y las nuevas tendencias

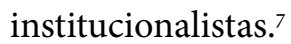

En lo referente a su efectividad, y precisamente debido a su carácter privado, las sanciones internacionales persiguen obtener la conducta deseada del sancionado para sobrevivir como tales. La efectividad está ligada a factores fácticos como el de relación o grado de dependencia e interdependencia y diferencias de poder o asimetría entre el sancionador y el sancionado. Mientras mayor sea la dependencia del sancionado frente al sancionador, mayor el impacto de las sanciones y mayor su efectividad; lo mismo sucede con la interdependencia: mientras esta sea mayor, mayores serán los efectos. En cuanto a la relación de poder, solo el Estado sancionador con mayor poder puede hacer uso de sanciones efectivas contra el Estado sancionado de menor poder; y mientras más grande su asimetría, mayor su efectividad, y al revés. Es poco concebible entonces que un Estado como Corea del Norte o Bolivia imponga sanciones contra Estados Unidos, ya que estas no tendrían visos de efectividad y serían además contraproducentes al provocar múltiples medidas sancionadoras por parte de este último, por la simple razón de disponer de recursos sancionadores casi ilimitados contra ellos. Esta situación convierte a las sanciones a su vez en discriminatorias, debido a la inmunidad material de Estados poderosos hacia ellas y a la alta vulnerabilidad de Estados débiles. ${ }^{8}$

Sus formas clásicas principales son la retorsión, represalia, bloqueo, intervención y guerra, ${ }^{9}$ que siguen teniendo validez actual. La primera de ellas, la retorsión, es una medida hostil que no representa en sí una violación a un derecho del Estado sancionado, sino solo una mera afectación a sus intereses, como la cancelación de

6. Las sanciones del capítulo 7 de la Carta de la ONU son también en esencia políticas, debido precisamente al carácter hegemónico del Consejo de Seguridad. Es un mito asegurar que este «club de poder sancionador» ejerce una «función pública mundial» de guardián del derecho internacional. Este aspecto de las sanciones internacionales es meramente descriptivo y no pretende ser categórico.

7. Se trata de posiciones idealizadas de la ONU que no reflejan la realidad; relacionada con la doctrina de la «personalidad internacional objetiva», como se desprende de la Opinión Consultiva de la CIJ, «Reparación por daños sufridos en el servicio de las Naciones Unidas», del 11 de abril de 1949.

8. Joyner y Ronzitti resaltan este desbalance en las sanciones: «Los Estados débiles sujetos a contramedidas están imposibilitados de oponerse efectivamente a ellas" (Ronzitti, 2016: 1), la traducción es mía. Más claro Joyner: "Las sanciones económicas, ya sea impuestas unilateralmente o por la ONU, se han convertido en una herramienta cada vez más utilizada de la diplomacia coercitiva, particularmente por Estados poderosos y organizaciones internacionales contra Estados débiles, Estados en desarrollo" (Joyner, 2017: 105), la traducción es mía.

9. A partir de la clasificación de las sanciones materiales de J. Dumas, véase «Sanktion» en Schlochhauer y Strupp (1963: 160). 
una cumbre de cooperación bilateral. A diferencia de la retorsión, la represalia, que en su forma moderna lleva el nombre de contramedidas, es una medida que sí afecta derechos iusinternacionales del Estado sancionado, por haber violado antes derechos del Estado sancionador. El bloqueo ha sido originalmente una medida de fuerza en la guerra marítima, que consiste en el cierre de una zona costera del Estado sancionado por fuerzas militares del Estado sancionador para impedirle el comercio marítimo con el exterior; concepto que en la actualidad se ha extendido al ámbito económico. La intervención militar es también considerada como una forma de sanción, si es respuesta a una violación previa de normas iusinternacionales. La guerra, como forma más extrema de sanción permitida por el derecho internacional clásico y moderno, es decir, como ultima ratio, solo está permitida actualmente en su forma colectiva en el marco de Naciones Unidas.

La distinción clásica de las sanciones según el sujeto activo o sancionador ha prevalecido y tiene incluso importancia crucial en el derecho internacional público de hoy. Así, se distingue entre sanciones colectivas o multilaterales, y sanciones individuales o autónomas. ${ }^{10}$ Las primeras, impuestas bajo el sistema de seguridad colectiva de Naciones Unidas u otra organización internacional regional, presentan un menor grado de descentralización y están en proceso creciente de institucionalización. Las segundas, ya sea en su forma individual o grupal fuera del marco de la ONU, presentan aún un alto grado de descentralización, es decir, se desenvuelven de acuerdo con el derecho de autotutela de los Estados con su principio judex in causa sua y se identifican con la figura clásica de las represalias en su denominación moderna de contramedidas. Esta distinción nos acompañará para conocer más en concreto las sanciones internacionales impuestas a Corea del Norte.

\section{Sanciones colectivas o multilaterales}

Las sanciones colectivas o multilaterales, o simplemente "sanciones de la ONU», están incrustadas dentro del sistema de seguridad colectiva de Naciones Unidas y conservan una estructura horizontal, aunque con un grado más alto de institucionalización que otras formas clásicas de sanción. ${ }^{11}$ Tampoco son un fenómeno nuevo, característico de la ONU, sino que tienen uno de sus precedentes más lejanos en las anfictionías griegas y el más reciente en la Liga de Naciones. ${ }^{12}$ Su connotación

10. La distinción es crucial en el derecho internacional público (Pellet y Miron, 2011: párr. 6).

11. Como las represalias colectivas en el derecho internacional consuetudinario, fuera del marco de la ONU. Estas son medidas de una organización internacional contra terceros afectada por la violación de una norma internacional, por ejemplo, las represalias de la Comunidad Europea contra Argentina en el conflicto de las islas Malvinas (Bleckmann, 1982: 2 y ss.).

12. Otras formas históricas se encuentran en la Liga Hanseática teutónica de la Edad Media, en los sistemas de seguridad colectiva de la Paz de Westfalia de 1648 y la Santa Alianza del siglo XIX. 
especial es que cuentan técnicamente con un mecanismo sancionador más efectivo y centralizado contra quienes amenacen o quebranten la paz internacional. Cuentan además con un espectro amplio de medidas, como las diplomáticas, pasando por las económicas, hasta llegar al recurso a la guerra. En el caso de esta última, el revestimiento del poder sancionatorio es central y va de la mano con la prohibición a todos los Estados miembros no solo de no recurrir a la guerra, sino al uso de la fuerza por su cuenta si no es en legítima defensa; norma que ha alcanzado la categoría de jus cogens con efectos erga omnes, es decir, es obligatoria para todos los Estados miembros y no miembros de Naciones Unidas.

Las sanciones colectivas en general han sido definidas por la Comisión de Derecho Internacional como medidas reactivas aplicadas a partir de una decisión tomada por una organización internacional competente, quien ha delegado su aplicación al Estado afectado mismo, a otros Estados o a todos los Estados miembros de la organización (Malanczuk, 1983: 718). De manera similar, se las concibe como medidas coercitivas previstas, decididas o recomendadas por una organización internacional competente para tal fin y en el marco de las disposiciones de su tratado de fundación, y según el procedimiento establecido en ella, contra un miembro que no ha cumplido con su obligación basada en el tratado; o contra terceros, de tratarse de una violación de obligaciones erga omnes. ${ }^{13}$ Se tiene como características esenciales de ellas, además de la coercividad, la disuasión que es el ejercicio de presión sobre su destinatario para que cambie de conducta o abandone el acto desaprobado. Se les atribuye también un carácter preventivo, mas este no siempre está presente en la práctica de las sanciones de la ONU, por encontrarse sanciones punitivas en ellas. ${ }^{14} \mathrm{Su}$ fin es esencialmente político, el mantenimiento de la paz, que significa que no requieren la previa violación de una obligación iusinternacional o la existencia de agraviados o víctimas, sino solo cualquier acción que, según la opinión de Naciones Unidas, quebrante o amenace la paz internacional. ${ }^{15}$ Estas sanciones tienen expresión principalmente en la ONU, y de forma complementaria o secundaria, en algunas organizaciones regionales dotadas de un mecanismo de seguridad colectiva, como la Unión Europea, la OEA, la Liga Árabe, la ASEAN y la Unión Africana. Nos ocuparemos de las sanciones de la ONU por ser cruciales en el caso norcoreano.

13. Entre ellas están la prohibición de la agresión, del genocidio, de la esclavitud y discriminación racial. Véase la sentencia de la Corte Internacional de Justicia del 5 de febrero de 1970, Barcelona Traction, ICJ Rep. 1970, 3.

14. Como la persecución penal a individuos por crímenes mayores mediante tribunales penales. En contra está la apreciación de la naturaleza preventiva, no punitiva de las sanciones en la sentencia sobre el caso Kadi del Tribunal de Justicia de la Unión Europea (Gran Sala), del 18 de julio de 2013, párr. 130. Sobre sanciones de la ONU como medidas represivas, Conlon (1996, 5 y ss.).

15. Aserción que pertenece a la técnica jurídica del régimen de sanciones de Naciones Unidas. A esto, entre otros, Ruys (2017: 23, 36). 
La sanciones colectivas de Naciones Unidas han experimentado un desarrollo sorprendente en los años noventa, $\mathrm{o}$ «década de las sanciones» (Cortright y Lopez, 2002: passim), producto de su práctica frecuente unida a la expansión de su concepto de «amenaza a la paz» a los más diversos tipos de situaciones y riesgos, como violaciones de derechos humanos y del derecho humanitario, conflictos armados, situaciones de emergencia humanitaria, terrorismo, proliferación nuclear y de armas de destrucción masiva, cambios «ilegales» de Gobierno, Estados caídos, etcétera. ${ }^{16}$ De igual forma han extendido el ámbito de los destinatarios a individuos, élites o grupos de poder, organizaciones terroristas, etcétera, fenómeno llamado también «movimiento de individualización» (Herik, 2017: 1, passim) bajo la idea de la «humanización de las sanciones», el que a su vez ha dado auge a las sanciones selectivas o inteligentes, de las que nos ocuparemos más adelante. Como consecuencia lógica de estos cambios, ha aumentado el nivel de organización de este mecanismo sancionatorio y se han perfilado sus técnicas de efectividad, en especial en su aplicación, seguimiento y cumplimiento; pudiéndoselo calificar como proceso de diversificación y multiplicación sustancial, y perfeccionamiento formal, a lo que unos autores califican también como proceso de formalización e individualización (Herik 2017, 1ss; Ruys 2017, 23, passim). De todo este complejo sancionatorio resaltan las sanciones económicas que son las más empleadas, tienden a ser más efectivas y fueron empleadas exclusivamente en el caso norcoreano, quedando fuera de alcance la opción de la intervención militar por los vetos chino y ruso en el Consejo de Seguridad.

\section{Sanciones colectivas económicas de Naciones Unidas}

Las sanciones económicas de la ONU, como de los Estados por su cuenta, están experimentando un nuevo apogeo como herramienta de política coercitiva y arma económica (Joyner, 2017: 113, passim) contra los sancionados. En el caso de Naciones Unidas, constituyen el instrumento político más poderoso, aparte del uso de la fuerza, en su función de mantenimiento de la paz y seguridad internacional, además de ser el empleado con más frecuencia. Fueron impuestas antes de 1990 en Rodesia del Sur y Sudáfrica, ${ }^{17} \mathrm{y}$ a partir de 1990 en numerosos casos, como Irak, Serbia y Montene-

16. Tras las sanciones contra Rodesia en 1966, el Consejo de Seguridad ha establecido 25 regímenes de sanciones con diversos objetivos: restauración del sistema democrático (Haití); cese de la opresión de la población (Myanmar, Nigeria, Afganistán); lucha contra el terrorismo con apoyo estatal (Sudán, Libia, Irán, Afganistán); cese de guerras civiles (Yugoslavia, Sierra Leona, Angola); ayuda humanitaria a la población civil, cumplimiento de los derechos humanos (Darfur), lucha por la no proliferación nuclear (Irán, Corea del Norte), protección de civiles (Libia), lucha contra la proliferación de armas de destrucción masiva (Irak, Libia, Irán y Corea del Norte).

17. Contra Rodesia del Sur, sanciones económicas: UN Doc S/RES/232 (1966), S/RES/258 (1968), S/ RES/277 (1970). Contra Sudáfrica, sanciones económicas no obligatorias: UN Doc S/RES/418 (1977). 
gro, Somalia, Liberia, Libia, Haití, Angola, Ruanda, Sudán, Sierra Leona, YugoslaviaKosovo, Afganistán, Irán y Corea del Norte. ${ }^{18}$

Comprenden entonces cualquier medida coercitiva decidida o recomendada por la ONU consistente en la limitación o suspensión de relaciones económicas con el Estado destinatario de la sanción, las que persiguen menoscabar de forma relevante su situación económica con la participación de todos los Estados, y teniendo el objetivo próximo de que se elimine aquella «irregularidad» identificada como causa de perturbación de la paz. Concepto en el que están incluidas las sanciones financieras en todas sus formas. El marco legal está en el artículo 41 de la Carta (capítulo 7), referido a las sanciones no militares. El órgano autorizado para imponerlas es el Consejo de Seguridad, que puede recomendarlas o imponerlas obligatoriamente a los Estados miembros según los artículos 25 y 48, en conexión con el artículo 103 de la Carta. Ya que por regla no tienen aplicación inmediata, deben ser implementadas en los sistemas legales de los Estados miembros. Su efectividad depende, pues, en gran parte de la participación efectiva de todos los Estados y, sobre todo, de los que mantienen significativas relaciones económicas con el sancionado, quienes deberán crear leyes nacionales o regionales con control de fronteras y de contrabando. La experiencia demuestra como tendencia que mientras más débil sea el Estado económicamente, más vulnerable es a las sanciones; y, al contrario, mientras más fuerte, serán menos efectivas. Por otro lado, tienen la característica especial de ser más descentralizadas que las sanciones militares de la ONU, lo que significa que en la práctica los Estados pueden extender al infinito - vía interpretación, implementación o en forma adicional- las sanciones colectivas de Naciones Unidas, por el hecho de que no existe una prohibición de su extensión más allá del marco dado en la resolución que las crea.

Sus formas más conocidas son el embargo, el boicot y el bloqueo. El embargo restringe o suspende la importación o exportación de productos o servicios con el Estado sancionado. El boicot, que no encuentra una definición cierta en el derecho internacional público, se confunde con el embargo y se tiene como una medida pasiva de abstención de la adquisición de productos o servicios del sancionado. El bloqueo o sitio, que se ejercita generalmente en alta mar, es la creación de un cerco mediante barcos de guerra o aviones, destinado a impedir el tránsito de barcos del Estado sancionado y hacia él. Se trata de una medida subsidiaria si es impuesta como ejecución de las sanciones económicas, que tiene la tarea concreta de supervisar y controlar el embargo impuesto al Estado sancionado. El bloqueo como simple ejecución de sanciones económicas no se tiene como «sanción militar», pero tampoco es una medida anexa a las sanciones económicas y tiene que imponerse expresamente por el Consejo de Seguridad.

Las sanciones económicas de la ONU pueden ser impuestas de forma gradual,

18. Para un cuadro más completo hasta 2001, Cortright y López (2002: apéndice A). 
de «sanciones simples» que afectan primero a uno o más sectores económicos, hasta llegar a sanciones generalizadas que impactan seriamente su economía cuando el Estado sancionado no cumple con la conducta exigida. Estas últimas fueron impuestas en los casos de Rodesia, Irak, la antigua Yugoslavia y Haití; pero en los años noventa, en especial en estos tres últimos casos, fueron objeto de críticas por el gran impacto negativo en la población, lo que desembocó en crisis humanitarias. A pesar de esta crítica, no se buscaron formas de moderación y limitación de las sanciones de la ONU por los problemas serios de equidad que traían consigo; por el contrario, aparecieron nuevas técnicas más precisas de sanciones, a las que se llamó sanciones selectivas o «inteligentes».

\section{Sanciones selectivas o «inteligentes» de Naciones Unidas}

Las sanciones selectivas — llamadas también «inteligentes», «dirigidas» $\mathbf{O}$ «individuales»- empezaron a ser utilizadas como regla general a mediados de los años noventa a causa de los daños colaterales a la población civil que generaron las sanciones económicas generalizadas de la ONU, como se acaba de ver. Son una forma de sanciones no militares más «dosificadas», dirigidas a sectores específicos o determinados individuos, grupos o entidades, a fin de evitar, o por lo menos disminuir, daños en la población civil del Estado sancionado, y conseguir mayor efectividad. ${ }^{19}$ No son una nueva forma de sanciones, sino de medidas conocidas en la práctica de la ONU, con la diferencia en la dosis de la medida y en su individualización. Se dieron por primera vez en los casos de Rodesia y Sudáfrica, y continuaron en numerosos casos contra algunos Gobiernos de países en conflicto, grupos insurgentes como UNITA en Angola, los bosnio-serbios, los jemeres rojos; personas u organizaciones designadas de «terroristas», como los Talibán o Al-Qaida, y miembros de una élite de poder, como en Haití, Angola, Sierra Leona, Afganistán, Myanmar y últimamente contra el régimen de Gobierno de Corea del Norte.

Sus destinatarios son sectores determinados de la economía del Estado sancionado o personas naturales y jurídicas que estén en relación directa o indirecta con la causa de la sanción; los que a su vez son ingresados a una «lista negra» de sanciones. Entre las más frecuentes están el embargo de armas, sanciones financieras, el bloqueo del libre tránsito internacional, el congelamiento de cuentas y activos, restricciones diplomáticas, etcétera. Su fundamento legal está, como en las sanciones económicas,

19. «Una política de sanción inteligente es la que impone presión coercitiva a determinados individuos y entidades, y restringe determinados productos y actividades, minimizando a la vez consecuencias económicas y sociales a poblaciones vulnerables y terceros» (Cortright y López, 2002: 2; la traducción es mía). Estados que han promovido este tipo de sanciones: Suiza, Alemania y Suecia, con informes en los procesos de Interlaken, Bonn-Berlin y Estocolmo. Apoyando estos procesos, Biersteker (2001); Brzoska (2001), Wallensteen, Staibano y Eriksson (2003) y Cameron (2005). 
en el artículo 41 de la Carta, que ha podido ser aplicado a las sanciones contra individuos gracias a la laguna jurídica de este artículo que no prohíbe expresamente al Consejo de Seguridad esta clase de sanciones.

Nótese que esta forma dosificada de sanciones es controvertida. ${ }^{20}$ Las expectativas puestas a ellas no han sido colmadas y recientemente se aprecia el retorno de la euforia a la moderación, pues aparte de poseer la única ventaja de evitar daños generales a la población civil, afectan de forma masiva derechos fundamentales de individuos y entidades, y tienen iguales o incluso mayores problemas de efectividad que las sanciones generalizadas, ${ }^{21}$ como se observa claramente en el caso norcoreano. La ONU las ha impuesto en su reciente práctica casi exclusivamente, pero su baja efectividad la obliga a recurrir a las sanciones económicas generalizadas en casos duros o fuertes, como en el de Corea del Norte, con lo que se presenta otra vez el problema criticado en los años noventa.

En el caso específico de las sanciones a individuos, la ventaja de reducir o evitar daños colaterales a la población civil se paga con el alto precio de impedir y bloquear el goce de derechos fundamentales de los sancionados, por lo que son afectados los derechos civiles y políticos, y garantías procesales, reconocidos nacional e internacionalmente; los derechos de propiedad, de libre movimiento y libre ejercicio de una profesión; el goce del buen honor, el acceso a la justicia, el derecho a reparación, etcétera; los que a su vez son capaces de producir daños colaterales como la ruina financiera, daños en su reputación, en su bienestar y salud, y en su existencia. Su problema más serio no solo está en el elemento penal, que poseen implícitamente, visto en la técnica de listado sin previo proceso ni forma viable de pedir su revisión judicial o borrado; ${ }^{22}$ sino también en su multiplicación indeterminada por el número de Estados miembros de la ONU, más el número de organizaciones regionales que pueden extender y endurecer las sanciones o crear otras por la misma causa y contra el mismo sancionado.

En el caso norcoreano, le fueron impuestas sanciones económicas selectivas y ge-

20. «Sin embargo, la controversia en torno a la compatibilidad de las sanciones selectivas con los derechos humanos, y quizás más importante, el surgimiento de nuevas vías que permiten su revisión judicial, ha tenido el efecto perverso de reavivar el mayor uso de sanciones generalizadas por parte de los Estados» (Happold, 2016: 10; la traducción es mía).

21. Hacen hincapié en este punto Tostensen y Bull (2002, passim), Hufbauer y otros (2007) y Drezner (2011: 104).

22. El listado como «pena de muerte civil» en Meyer y Macke (2007: 445). Las sanciones se imponen sin examen de evidencia de que los afectados están envueltos en actividades que amenazan la paz y la seguridad internacional y el Consejo de Seguridad actúa como un órgano cuasicriminal de investigación, acusación y sentenciador (como servicio secreto, policía, fiscal y juez a la vez). Es casi imposible ser borrado de las listas negras, por estar sometido a veto. La creación de la Oficina del Ombudsman tiene sus limitaciones y solo es aplicable al régimen de sanciones de EIIL (Dáesh) y Al-Qaida. 
neralizadas de la ONU. En paralelo y de manera independiente se le impusieron, a su vez, sanciones unilaterales económicas selectivas y generalizadas por potencias occidentales, con alcance universal. En lo que sigue veremos cómo se presentan las sanciones colectivas de la ONU contra Corea del Norte, para luego referirnos a las sanciones unilaterales.

\section{Las sanciones colectivas de Naciones Unidas contra Corea del Norte}

\section{El marco político del conflicto nuclear norcoreano}

Las sanciones colectivas de la ONU - y también las unilaterales o autónomas- impuestas a Corea del Norte no pueden comprenderse seriamente sin conocerse el conflicto nuclear norcoreano yacente en ellas, el que se remonta en su momento más próximo al nuevo orden posbélico de la Guerra Fría producido por el fin de la Segunda Guerra Mundial, y se hace visible desde comienzos de los años noventa con la primera crisis nuclear. Tres actores están envueltos en él y solo de ellos depende el resultado definitivo del conflicto: Estados Unidos, Corea del Norte y Corea del Sur, quienes jurídicamente se encuentran aún en estado de guerra y en la práctica en un estado de constante tensión. De ahí que los asuntos de defensa en la península de Corea sean en extremo delicados y hayan tenido alta prioridad para estos tres Estados hasta el presente, relación triádica en que el arma nuclear juega como un elemento esencial y constante de disuasión. La península, que comprende ambas Coreas, es pues una zona altamente militarizada y nuclearizada. Su militarización empezó con la ocupación estadounidense y soviética al fin de la Segunda Guerra Mundial y desde la guerra de Corea en 1950. Su nuclearización empezó en 1958, con la instalación de armas nucleares en territorio surcoreano, precisamente por Estados Unidos y Corea del Sur, como instrumento de disuasión, primero contra Corea del Norte, y por extensión contra China y la Unión Soviética; proceso de nuclearización que duró 33 años bajo las protestas de Corea del Norte por violación del armisticio de $1953(\mathrm{Cu}-$ mings, 2004: 52 y ss.). ${ }^{23}$ Su retiro en 1991 no significó su eliminación de la península de Corea, sino, por el contrario, su sustitución por armas nucleares estratégicas estadounidenses ${ }^{24}$ que hasta el presente forman parte esencial del «paraguas nuclear» o protección nuclear en la política estadounidense de disuasión y defensa de Corea

23. Armisticio que prohibía la introducción de armamento cualitativamente nuevo, el que además estaba dirigido a Corea del Norte. Los ejercicios bélicos periódicos desde los años sesenta preveían el uso temprano de las armas nucleares en caso de una confrontación armada.

24. Entre ellas, los bombarderos con capacidad nuclear (por ejemplo, el cazabombardero B-52) y submarinos de misiles balísticos (nucleares) estacionados en distinto puntos, los que reemplazaron por completo a las fuerzas tácticas nucleares o armas nucleares no estratégicas después de su retiro en 1991. Más detalles en Kristensen y Norris (2017). 
del Sur y Japón. Asimismo, el mantenimiento de más de quince bases militares con el estacionamiento permanente de unos 28,500 soldados estadounidenses en Corea del Sur desde 1957, junto con los entrenamientos militares periódicos a gran estilo para casos de guerra convencional y nuclear en territorio surcoreano, son muestras claras del factor detonante que encierra este conflicto no solucionado hasta hoy. ${ }^{25}$ Con estos datos fácticos, sale a nueva luz el conflicto nuclear norcoreano, y relativiza en forma significativa la imagen corriente y simplista occidental que se tiene de él. De estos tres actores del conflicto, las posiciones más irreconciliables se encuentran entre Estados Unidos y Corea del Norte, mientras que Corea del Sur cumple el papel más moderado pero a la vez atado, amarrado voluntariamente a la política de Estados Unidos en los asuntos de su seguridad y defensa, no solo como su aliado fiel y fidedigno, sino también como Estado subalterno sin soberanía defensiva.

La primera gran crisis nuclear ocurrida entre 1991 y 1994, que estuvo a un paso de la confrontación bélica, fue ante todo un conflicto entre Estados Unidos y Corea del Norte, el cual se zanjó en último momento con la firma del Acuerdo Marco entre ambos Estados ${ }^{26}$ e hizo innecesaria la imposición de sanciones de la ONU. ${ }^{27}$ En aquel momento, Estados Unidos se enfrentaba a una Corea del Norte que hacía uso de la energía nuclear para fines civiles o pacíficos, era miembro del Tratado de No Proliferación de Armas Nucleares desde 1985 (TNP), había suscrito las debidas garantías en 1992 y era miembro del Organismo Internacional de Energía Atómica (OIEA) desde 1974. Este acuerdo logró que Corea del Norte permaneciera en el TNP, se sometiera a la inspección internacional acuciosa de sus plantas nucleares y, quizás lo más importante, que Estados Unidos le brindase, por escrito, garantías de no agredirlo, aparte de su promesa de proporcionarle el debido sustituto para el desmantelamiento

25. Los que han sido objeto de protestas por Corea del Norte e interpretados como una amenaza constante de agresión. Las tropas estadounidenses están estacionadas desde el 1 de julio de 1957 con fuerzas armadas terrestres, aéreas y navales al mando de las Fuerzas Armadas de Estados Unidos en Corea del Sur y del Comando del Pacífico de Estados Unidos (PACOM). Corea del Sur es desde entonces territorio de un gran número de bases militares y depósito de armas en diferentes puntos del país. Los costos de esta presencia estadounidense se estiman de unos USD 17.000 a 42.000 millones anuales (Cumings, 2004: 75).

26. Suscrito el 21 de octubre de 1994. Corea del Norte se compromete a no retirarse del Tratado de No Proliferación de Armas Nucleares (TNP), desmantelar sus reactores moderados de grafito e instalaciones, renunciar al reciclaje de combustible nuclear residual y a acceder a inspecciones completas del Organismo Internacional de Energía Atómica (OIEA). A cambio, Estados Unidos le suministraría a Corea del Norte 500.000 toneladas anuales de fuelóleo pesado y reactores de agua ligera para su funcionamiento en 2003, a otorgarle la garantía de no amenazarla o agredirla con armas nucleares y comenzar relaciones diplomáticas y de cooperación técnica nuclear (UN Doc INFCIRC/457, 2 de noviembre de 1994).

27. El Consejo de Seguridad se limitó a amonestar a Corea del Norte por su declaración de retiro del TNP, UN Doc S/RES/825 (1993). 
de sus plantas nucleares cuestionadas. Este acuerdo de mutuo beneficio para ambas partes fracasó en la ejecución, y no tanto por parte de Corea del Norte, sino más por el lado estadounidense, quien no procuró la financiación requerida para el proyecto de cooperación sustitutoria nuclear, pues la administración Clinton dejó truncado el proyecto al final de su Gobierno, y terminó rápidamente en la papelera de su sucesor, George W. Bush. ${ }^{28}$

\section{Las sanciones de Naciones Unidas en la fase} del golpe militar latente de George W. Bush

La Administración de George W. Bush (2001-2009) tuvo en primer orden la solución militar del conflicto nuclear norcoreano con su política de «contraproliferación activa» (Münkler, 2006: 186) extremadamente hostil contra Corea del Norte. Su calificación de Estado «paria» o «ilegal», con el consiguiente ingreso en la lista del «Eje del Mal», junto a Irak e Irán, le facilitaría la justificación a sus acciones de aislamiento del régimen norcoreano y el rechazo de negociaciones directas con él; política que era expresión de un no reconocimiento claro e inequívoco. Bajo esta constelación política negativa, Corea del Norte decidió reiniciar su programa nuclear justificándolo como «defensa de su soberanía y derecho de existencia frente a la amenaza desbordante nuclear estadounidense» (Cumings, 2004: 91; la traducción es nuestra), se retiró del TNP el 10 de enero de 2003 y volvió a poner en función su instalación de plutonio unos meses después; actos confrontativos que hicieron más palpables el peligro de una intervención militar estadounidense en Corea del Norte y de un enfrentamiento bélico. ${ }^{29}$ Pero China se interpuso entre los dos y, sobre todo, en los planes bélicos estadounidenses con su mediación diplomática, al crear e impulsar un foro de negociación multilateral de seis Estados para solucionar el conflicto nuclear norcoreano, el que fue aceptado - no con gusto- por Estados Unidos. El Grupo de las Seis Partes no se creó para «convencer a Corea del Norte de que se detracte de su intención de producir armas nucleares y se siente a la mesa de negociación», como se afirma en la literatura corriente, sino para traer a ambos Estados a la mesa de negociación y quitarle a Estados Unidos la justificación de agredir militarmente

28. El Acuerdo Marco fue cumplido en gran parte por Corea del Norte, pues esta clausuró sus reactores nucleares e instalaciones de plutonio (su reactor de $5 \mathrm{MW}$ ) en Yongbyon, aceptó las rondas de inspecciones de la OIEA, reformó sus leyes para facilitar la creación de joint ventures e inversión extranjera en 1995 y suspendió su retiro del TNP. Estados Unidos solo avanzó con lo acordado con lentitud: la construcción de los reactores, que estuvo a cargo de la KEDO (Organización para el Desarrollo de la Energía de la Península de Corea), se truncó a falta de financiación del consorcio integrado por Estados Unidos, Japón y Corea del Sur. George W. Bush resolvió el proyecto definitivamente.

29. El peligro concreto de una intervención militar se observaba en el traslado de aviones de combate y armamento pesado a la zona del Pacífico y Corea del Sur a comienzos de 2003, a esto Feffer (2004: 9). 
a Corea del Norte. Este proceso de diálogo pudo «arrancar» de esta superpotencia algunas concesiones hacia Corea del Norte a cambio de que esta vuelva a someterse a control nuclear internacional. ${ }^{\circ 0}$ Sin embargo, el Grupo no pudo impedir la espiral de sanciones unilaterales y ensayos nucleares en que cayeron estos dos Estados, lo que resultó en el endurecimiento de las sanciones estadunidenses y la agilización del programa nuclear y balístico norcoreano, al punto de que Corea del Norte se declaró como potencia nuclear en $2005^{31}$

Las primeras sanciones colectivas de la ONU contra este Estado comenzaron al año siguiente, en 2006, con sanciones no obligatorias (Resolución 1.695, de 2006), ${ }^{32}$ en reacción a un ensayo balístico norcoreano, y sanciones obligatorias con la Resolución 1.718, del 14 de octubre de 2006, como respuesta a su primer ensayo nuclear el 9 de octubre de 2006. La Resolución 1.718 del Consejo de Seguridad inició el régimen de sanciones obligatorias y progresivas contra Corea del Norte bajo el capítulo 7, después de calificar la tensión creada por el ensayo nuclear como «amenaza a la paz», e imponerle un paquete de exigencias, como la abstención de ejecutar ensayos nucleares y lanzamientos de misiles balísticos; el abandono de todas las armas nucleares y misiles balísticos de manera completa, verificable e irreversible, incluyendo las armas de destrucción masiva; la actuación conforme a las obligaciones del TNP y su reincorporación a este; y el otorgamiento de las salvaguardias a la OIEA. Seguido de ello, impuso sanciones económicas selectivas consistentes en un embargo de armamento militar convencional pesado y de productos conexos a armas y tecnología nuclear, balística y de armas de destrucción masiva en ambas direcciones, incluyendo el suministro de asistencia técnica relacionada y de productos de lujo a Corea del Norte. Como complemento, impuso sanciones individuales como el congelamiento de fondos, activos financieros y bloqueo del tránsito internacional a personas o enti-

30. El Grupo de los Seis se creó en 2003 con la participación de China, Corea del Sur, Rusia, Japón, Corea del Norte y Estados Unidos. Se reunió en seis rondas desde abril de 2003 a octubre de 2007 y llegó a tres acuerdos: del 19 de septiembre de 2005, del 13 de febrero de 2007 y del 3 de octubre de 2007. Se basaron en concesiones mutuas de desnuclearización a cambio de cooperación energética por parte de Estados Unidos y proceso de diálogo y relaciones bilaterales; la implementación también debía calibrarse de forma mutua, más detalles en Fu (2017: 9 y ss.). Las sanciones solo formaron parte secundaria en las negociaciones.

31. A la declaración oficial norcoreana del 10 de febrero de 2005 de estar en posesión de armas nucleares, Estados Unidos respondió con sanciones financieras unilaterales y con planes de un «golpe militar preventivo"; le siguieron una serie de sanciones en 2005 y 2006, que se intercalaron con los ensayos nucleares norcoreanos. Las crecientes sanciones estadounidenses provocaron al fin que Corea del Norte intentase dejar las negociaciones de las Seis Partes, más detalles en Fu (2017: 3 y ss.).

32. UN Doc S/RES/1695(2006), del 15 julio de 2006, en respuesta al ensayo balístico norcoreano del 5 de julio, recomienda un embargo a la importación y exportación de materiales, productos y tecnología balística y nuclear, y embargo financiero a este sector, sin referirse expresamente al capítulo 7; sobre la obligatoriedad jurídica de esta resolución, véase Yong-Joong Lee (2007). 
dades relacionadas con las actividades nucleares, balísticas y de armas de destrucción masiva, y familiares. Para la organización y control de este régimen de sanciones, creó un comité, también a cargo del manejo de los listados. ${ }^{33}$ Esta última resolución sirvió como base de las demás sanciones obligatorias que le siguieron.

\section{Las sanciones de Naciones Unidas en la fase de aceleración nuclear norcoreana}

La esperanza en una política más apta al diálogo y negociación se desvaneció en Corea del Norte tan pronto Barack Obama asumió el Gobierno estadounidense (20092017). Su política de «paciencia estratégica» (véase Delury, 2016) fue de continuidad con las políticas de sus antecesores, fundada en el no reconocimiento del régimen de Gobierno norcoreano y en su negativa de entablar negociaciones directas con él; lo que no significa no entrar en diálogo con Corea del Norte en absoluto, sino en hacerlo de manera discreta, a un nivel diplomático bajo y con mediadores. A falta de un diálogo serio, ambos Estados continuaron la espiral de ensayos y sanciones, que ya se observaba con el Gobierno de George W. Bush. Fue probablemente debido a la falta de un plan o estrategia de solución de la administración Obama, ya sea por la vía diplomática o militar, que Corea del Norte aceleró aún más su programa nuclear y balístico, ${ }^{34}$ lo que resultó en cuatro ensayos nucleares y diversos lanzamientos de misiles balísticos que la llevaron a la posesión de un arsenal nuclear desarrollado, con su correspondiente tecnología, y la catapultaron en potencia nuclear de facto, al lado de Israel, India y Pakistán. Ello a pesar de todo el peso, ya bastante fuerte, de las sanciones de la ONU y sanciones unilaterales. Todas ellas no solo no lograron reconducir la conducta nuclear norcoreana en sentido de sus exigencias, sino que consiguieron el resultado contrario.

Tres años después de la Resolución 1718 (2006), y como reacción al segundo ensayo nuclear norcoreano del 25 de mayo de 2009, el Consejo de Seguridad impuso mediante Resolución 1.874, del 12 de junio de 2009, un embargo general de armas y armamento, exceptuando la venta a Corea del Norte de armas pequeñas y ligeras; asimismo, extendió el embargo financiero sobre toda actividad relacionada con los programas nuclear, balístico y de armas de destrucción masiva, y creó un mecanismo de inspecciones con la autorización a todos los Estados de realizarlas frente a navíos

33. UN Doc S/RES/1718(2006). Sus prerrogativas fueron ampliadas por las Resoluciones 1.874, $2.087 \mathrm{y}$ 2.094; tiene la función de enlistar y borrar de las listas a personas y entidades.

34. El diálogo norcoreano-estadounidense continuó de fondo con mediación china, hasta que el 29 de febrero de 2012 se llegó a un «acuerdo de día bisiesto» (leap day agreement) que entre otras cosas fijaba una moratoria norcoreana de ensayos nucleares de misiles de largo alcance y readmisión de las inspecciones de la OIEA, mientras que Estados Unidos se comprometía a suministrarle alimentos nutricionales, fomentar la confianza y cooperación, y ambas partes a seguir con la implementación del Acuerdo Conjunto del Grupo de las Seis Partes del 19 de septiembre de 2005. 
norcoreanos sospechosos de violar el embargo, más su incautación y eliminación. Creó también un grupo de expertos como órgano de apoyo y asesoría al Comité. ${ }^{35}$ Estas sanciones, que han sido extensivas y duras por menoscabar en la defensa nacional del país y privarle de la generación de divisas de la venta de armas, tampoco condujeron a que Corea del Norte abandone su programa nuclear y balístico.

En un intervalo de algo más de tres años después de la Resolución 1.874, el Consejo de Seguridad entró en una fase breve de nuevas sanciones selectivas contra el país. La primera, con la Resolución 2.087, del 22 de enero de 2013, y como respuesta al lanzamiento del satélite norcoreano Unha-3 del 12 diciembre de 2012, congeló los fondos, activos financieros y recursos económicos en el extranjero y bloqueó el tránsito internacional a empresas y personas de altos cargos comprometidas con el programa de misiles balísticos. ${ }^{36} \mathrm{La}$ segunda, mediante Resolución 2.094, del 7 de marzo de 2013 y en respuesta al tercer ensayo nuclear norcoreano del 12 de febrero de 2013, extendió el embargo financiero al sector bancario norcoreano, instó la vigilancia del personal diplomático norcoreano y reforzó más el mecanismo de inspecciones de navíos y aviones, así como la expulsión de personas sospechosas. ${ }^{37}$

Tres años después de la Resolución 2.094, el Consejo de Seguridad inició un nuevo periodo de sanciones colectivas más duras y generalizadas, que afectó los productos más importantes de importación y exportación norcoreanos y su economía en general. Así, en respuesta al cuarto ensayo nuclear norcoreano del 6 de enero de 2016 y su lanzamiento de satélite un mes después, el Consejo de Seguridad, en su Resolución 2.270, del 2 de marzo de 2016, impuso un nuevo paquete de sanciones, de las que resaltan el embargo absoluto de armas y del sector militar, incluyendo los servicios de cooperación militar, policial y paramilitar; la prohibición a los Estados de comprar carbón, hierro o mineral de hierro, oro, titanio, vanadio y tierras raras norcoreanos, permitiendo excepciones para el carbón bajo estrictas condiciones, aparte de extender la lista de personas y entidades sancionadas. ${ }^{38}$ Esta resolución extraordinariamente extensa - de 19 páginas - contiene, junto con la Resolución 2.321, las sanciones más duras desde las impuestas a Irak en los años 90 (Borlini, 2016: 1); pero, a diferencia de ese país, tampoco lograron cambiar la conducta de Corea del Norte, sino que continuó con su programa nuclear con más fuerza, y ese mismo año volvió a ejecutar un nuevo ensayo nuclear, el quinto, el 9 de septiembre de 2016. Como respuesta, el Consejo de Seguridad, mediante la Resolución 2.321, del 30 de noviembre de 2016, prohibió a Corea del Norte además ejecutar actos de lanzamiento de satélites

35. UN Doc S/RES/1874(2009). Sobre las dos primeras sanciones, véase Portella (2011).

36. UN Doc S/RES/2087(2013). A esto, véase Tariq Rauf, «North Korea's space launch», Stockholm International Peace Research Institute, 9 de febrero de 2016 , disponible en bit.ly/35 $\mathrm{BiD} 5 \mathrm{~F}$.

37. UN Doc S/RES/2094(2013).

38. UN Doc S/RES/2270(2016). 
al espacio. Este documento, igual de extenso que el anterior, extiende el embargo absoluto de armas a las de doble uso; prohíbe la compra de carbón norcoreano, estableciendo vía de excepción cuotas límites, y extiende la prohibición de comprar minerales norcoreanos al cobre, níquel, plata y zinc; prohíbe además la cooperación científico-técnica con excepciones y el suministro de combustible de aviación a Corea del Norte; amplía la lista de artículos de lujo embargados; restringe las cuentas del personal diplomático y el uso de inmuebles en el extranjero a fines diplomáticos; amplía el listado a más personas y empresas, y ajusta más su mecanismo de inspecciones, entre otras prohibiciones y restricciones. ${ }^{39}$

\section{Las sanciones de Naciones Unidas con la politica de «presión máxima» de Trump}

En 2017, el nuevo presidente de Estados Unidos, Donald Trump (2017-2021), se enmarcó en la línea de continuidad de sus antecesores, pero a la vez le dio el matiz personal pragmático con una política de renuclearización, que prevé el desarrollo y empleo de nuevas armas nucleares en futuras contiendas militares ${ }^{40} \mathrm{y}$ de "presión máxima» hacia Corea del Norte. Con la continuación y extensión de los entrenamientos militares con Corea del Sur, ${ }^{41}$ vistos por Corea del Norte como una provocación o amenaza militar, se abrió nuevamente paso a una cadena de acontecimientos que caen en el mismo ritmo de ensayos y sanciones visto desde hace años. Corea del Norte ejecutó entonces de forma paralela varios ensayos de misiles balísticos que tuvieron su punto culminante en el primer ensayo de dos misiles intercontinentales (ICBM) el 4 de julio de 2017 y en el sexto ensayo nuclear del 3 de septiembre de $2017 .^{42}$ Como respuesta, el Consejo de Seguridad empezó una nueva ronda de sanciones que se impusieron hasta finales de 2017 y llegaron a la suma de cuatro con las Resoluciones $2.356,2.371,2.375$ y 2.397, cuando el país ya estaba siendo castigado fuertemente con las existentes que parecían haber llegado al tope de dureza.

39. UN Doc S/RES/2321(2016). Para el ex secretario general de la ONU, Ban Ki-moon, el texto contiene el régimen de sanciones más duro y general que se ha impuesto por el Consejo de Seguridad (Borlini, 2016: 3).

40. Véase Kristensen y Korda (2020).

41. «Key Resolve» $\mathrm{y}$ «Foal Eagle» en marzo y abril de 2017, incluyendo entrenamientos con armamento nuclear. Duró esta vez dos meses, con la participación de 320.000 soldados surcoreanos y estadounidenses; se entrenó con armas nucleares en gran estilo, como bombarderos no detectables por radar, portaviones nucleares como el USS Carl Vinson, y submarinos con misiles nucleares. Nuevamente en agosto se llevaron a cabo las maniobras militares «Ulchi Freedom Guardian», en que se practicaron, entre otros ejercicios, golpes preventivos (preemptive strikes); provocaron protestas y amenazas de Corea del Norte. James Law, «Why US-South Korea military drill could provoke North Korea's ire», NZ Herald, 15 de Agosto de 2017, disponible en bit.ly/3gORO3f.

42. Ensayo de una bomba de hidrógeno miniaturizada, capaz de ser transportada por un misil intercontinental, según fuentes de información norcoreana. 
Con la Resolución 2.356, del 2 de junio de 2017 el Consejo de Seguridad extendió la lista de congelación de fondos y prohibición de tránsito internacional a más personas, entidades y personal del Gobierno, en respuesta de los lanzamientos de misiles balísticos norcoreanos. ${ }^{43}$ Con la Resolución 2.371, del 5 de agosto de 2017, y en respuesta al ensayo de misiles intercontinentales del 3 y 28 de julio, prohibió la compra de los productos norcoreanos de exportación más importantes: el plomo y productos pesqueros; restringió la contratación de personal norcoreano en el extranjero e incluyó a más personas y entidades en la lista de congelación de fondos y prohibición del tránsito extranjero. ${ }^{44}$ Un mes después, el 11 de septiembre de 2017 y en respuesta al sexto ensayo nuclear norcoreano del 2 de septiembre, en su Resolución 2.375 prohibió el suministro de condensados de gas natural y gases líquidos a Corea del Norte, de productos derivados del petróleo superior a un tope de dos millones de barriles anuales y de petróleo mayor a un tope establecido; prohibió la compra de productos textiles norcoreanos, la celebración de joint ventures con empresas norcoreanas y la contratación de mano de obra norcoreana en el extranjero; ingresó también a más personas y empresas en las listas negras y ajustó aún más su mecanismo de inspecciones. ${ }^{45} \mathrm{El} 22$ de diciembre de 2017 le siguió la Resolución 2.397, que redujo aún más los topes de suministro de petróleo crudo e hidrocarburos; prohibió la venta al país de maquinaria industrial, vehículos de transporte, hierro, acero «y otros metales»; prohibió la compra de productos agrícolas norcoreanos; impuso la repatriación de trabajadores norcoreanos en el extranjero; autorizó operaciones de interdicción marítima de navíos de carga norcoreanos y amplió el listado a más personas y entidades, como respuesta al lanzamiento del misil balístico intercontinental Hwasong-15, del 28 de noviembre de $2017^{46}$

Todas estas sanciones, que se dieron en once resoluciones, forman parte del régimen sancionatorio de la ONU contra Corea del Norte, y se dieron de forma graduada, es decir, primero con sanciones selectivas, que afectaron al sector militar y a individuos, y después con las generalizadas cuando no alcanzaron sus propósitos. Estas tampoco lo hicieron, pues este régimen sancionatorio enfrentó problemas de efectividad, pese a las técnicas perfiladas de implementación de las sanciones a cargo del Comité con su panel de expertos y del perseguimiento «religioso» de evasiones de los embargos con el amplio mecanismo de inspecciones.

$\mathrm{Al}$ año siguiente, en 2018, las relaciones entre Corea del Norte y Estados Unidos entraron en una fase de distensión con el acercamiento propulsado por el presidente de Corea del Sur, Moon Jae-in. De tres cumbres de jefes de Estado, solo la primera, la

\footnotetext{
43. UN Doc S/RES/2356(2017).

44. UN Doc S/RES/2371(2017).

45. UN Doc S/RES/2375(2017).

46. UN Doc S/RES/2397(2017).
} 
de Singapur el 12 de junio de 2018, produjo una Declaración Conjunta de desnuclearización norcoreana y garantías estadounidenses de no agresión. ${ }^{47} \mathrm{La}$ segunda, en la que se avanzaría sobre aspectos más concretos, fracasó precisamente por el tema de las sanciones. ${ }^{48}$ Trump no estuvo dispuesto a integrarlas en el proceso de diálogo de desnuclearización norcoreana, sino solo a levantarlas una vez que Corea del Norte entregue su programa nuclear de forma «irrevocable, supervisable y completa»; posición inflexible que no dio pie a la negociación y se acercó a una capitulación para Corea del Norte, ya que la desnuclearización sería un proceso técnicamente complejo que toma muchos años para llegar a su culminación. En cuanto al aspecto de fondo, Corea del Norte, en posesión del arma y tecnología nuclear, exige ser reconocida por lo menos como potencia nuclear de facto, al lado de Israel, India y Pakistán, reconocimiento difícil de otorgar desde el lado estadounidense, sobre todo por encontrarse aún en un cuasi estado de guerra con ella, aparte de su posición no negociadora en general con un régimen autoritario.

\section{Justificabilidad de las sanciones de Naciones Unidas a Corea del Norte}

Las sanciones de la ONU a Corea del Norte forman parte del régimen de no proliferación de armas nucleares y armas de destrucción masiva desarrollado por el Consejo de Seguridad en los últimos años del siglo $\mathrm{XX} ;{ }^{49}$ se trata de un mecanismo sancionatorio extenso, severo y consecuente en su cumplimiento mediante los comités de sanciones. Ya que las resoluciones impiden el goce de diversos derechos en diferente grado, es necesario cuestionar su legalidad aún bajo la llamada «presunción de legalidad». Un examen superfluo de justificación bajo la presunción de legalidad de las sanciones de Naciones Unidas conduciría a la aserción de que el Consejo de Seguridad ha procedido formal y materialmente de acuerdo con la Carta, ya que en este último caso se hace difícil encontrar elementos notorios de haber actuado contra sus propósitos y principios; concluyéndose que probablemente no han violado el derecho de autodeterminación del pueblo norcoreano, el derecho de preservación y defensa del Estado, el principio de igualdad soberana o la independencia política norcoreana con su derecho de ejercer el comercio libremente, el derecho de desarrollo, el derecho

47. La Declaración de Singapur. Frutos de ella son la declaración de Trump «Corea del Norte ya no es una amenaza nuclear», y la suspensión de los entrenamientos militares en Corea del Sur, véase Anne Flaherty, Adam Schrek y Foster Klug, «Trump dice que Norcorea ya no es amenaza nuclear», AP News, 13 de junio, 2018, disponible en bit.ly/2UyECb2.

48. Celebrada en Vietnam el 27 y 28 de febrero de 2019; la tercera, en la Zona Desmilitarizada de la frontera norcoreana el 30 de junio de 2019, solo fue un encuentro informal entre los dos mandatarios.

49. A raíz de los ensayos nucleares de India y Pakistán (Resolución CS 1.172 de 1998). Con la Resolución CS 1.540 de 2004, se crea un régimen internacional de contraproliferación nuclear y de armas de destrucción masivas, que las califica de «amenaza a la paz». 
de no intervención, y derechos fundamentales como el de propiedad o libertades básicas como la de movimiento y libre tránsito. Aquí se requiere de exámenes más profundos con respecto a cada uno de estos derechos afectados. Solo nos referiremos a dos aspectos dudosos de legalidad en cuanto las exigencias a Corea del Norte:

En primer lugar, tenemos la exigencia de retractarse de su retiro del Tratado de No Proliferación Nuclear (TNP), reincorporarse a él y cumplir sus obligaciones; cumplir con las salvaguardias de la OIEA y firmar la Convención sobre la prohibición de armas químicas..$^{50}$ Esta exigencia es producto de la calificación de «amenaza a la paz» a la tensión causada por los ensayos nucleares y balísticos norcoreanos. El Consejo de Seguridad se pudo haber limitado a exigirle la suspensión de tales actividades y de su programa. No es entonces acertado exigirle que cumpla con otros actos conexos no calificados directamente de «amenaza a la paz» y que caen dentro de la esfera de los derechos soberanos de Corea del Norte de actuar según sus intereses nacionales. El retiro del Tratado de no Proliferación Nuclear (TNP) en 2003 fue parte de su libertad de acción que poseen todos los Estados por igual, la que a su vez está reconocida en el Tratado (artículo 10). Lo mismo se puede decir de la exigencia de reincorporarse a él, pues no hay norma de derecho internacional público que le obligue a firmar un convenio cuando el Estado cree que va en contra de sus intereses, y el derecho internacional público prohíbe incluso la firma de un convenio por coacción..$^{51}$ Además, se encuentra el hecho de que el Tratado de no Proliferación Nuclear no puede servir como estándar moral, ya que no obliga a terceros, tiene un carácter sumamente controvertido y se encuentra actualmente en crisis..$^{52}$ Aquí se observa una extralimitación de sus exigencias que endurecieron más las sanciones.

En segundo lugar, tenemos la prohibición de sus actividades nucleares y balísticas, su suspensión y abandono de manera completa, verificable e irreversible..$^{53}$ Más serias connotaciones tiene este requerimiento, que igualmente se apoya en la idea de que la tensión causada por tales actividades constituye una «amenaza a la paz» — no las actividades y programa nuclear y balístico en sí- y están prohibidas aun así no violen el derecho internacional público. Este derecho en general no prohíbe la posesión de armas nucleares y misiles balísticos, sus correspondientes ensayos ni el rearme nuclear. ${ }^{54}$ Sus limitaciones solo son posibles mediante tratados como el TNP, o con-

50. UN Doc S/RES/1718(2006).

51. Artículo 51 del Convenio de Viena sobre el Derecho de los Tratados.

52. El TNP, en vigor desde 1970, es un convenio multilateral de seguridad nuclear internacional para evitar el exterminio de la raza humana por una guerra nuclear. Congela en la posesión de armas a los Estados que ya la poseen, en conexión con la renuncia a ellas de todos los demás Estados firmantes que aún no la poseen, a cambio de un derecho al uso pacífico de la energía nuclear y la promesa del desarme nuclear.

53. UN Doc S/RES/1718(2006).

54. Ni la Carta de la ONU ni ninguna norma consuetudinaria internacional las prohíben. Su prohibi- 
venios sobre la prohibición de ensayos nucleares ${ }^{55} \mathrm{O}$ prohibición de armas nucleares..$^{56}$ Corea del Norte no es parte de ninguno de ellos, hecho que la coloca en igual condición que las potencias nucleares de facto, Israel, India y Pakistán, que tampoco son partes del régimen convencional de no proliferación nuclear. La evidencia de su no prohibición está dada en la existencia de Estados que las poseen «legalmente» y de facto, los que por otro lado no pueden ser obligados al desarme nuclear. Tampoco se espera que exista en el futuro una norma general que prohíba la posesión de armas nucleares por la razón de que las potencias nucleares «legales» nunca renunciarán voluntariamente a su posesión.

Corea del Norte fundamenta sus actividades y programa nuclear y balístico en su libertad de acción y derecho fundamental de existencia y preservación, y, por ende, de su derecho innato de legítima defensa reconocido por el derecho internacional público (artículo 51 de la Carta de Naciones Unidas). Su derecho de igualdad soberana la protege además de discriminaciones en el trato sobre el tema nuclear. La justificación defensiva norcoreana de sus actividades y programa nuclear y balístico resulta ser a la vez elocuente en vista del mayor poder disuasivo de la fuerza militar estadounidense-surcoreana y la presencia militar activa estadounidense en la península de Corea. Por tanto, si la tensión que generan las actividades y programa nuclear y balístico norcoreano es considerada como «amenaza a la paz», con mayor razón tendrá que ser considerada como amenaza a la paz la tensión causada por la militarización y nuclearización estadounidense-surcoreana en la península, cuyo poder militar es muchísimo más desarrollado y fuerte que el norcoreano, sin hablar de su poder económico y político. Las razones de defensa norcoreana fueron indirectamente reconocidas por la Administración Trump al declarar que Corea del Norte ya no es una amenaza nuclear, y al otorgarle garantías de no agresión.

La justificación se hace más problemática en cuanto a la legitimidad. Esta empieza cuando los conflictos entre los Estados y en los Estados pueden resolverse dentro de un proceso jurídico por un tribunal internacional imparcial e independiente, con las garantías del debido proceso. La cuestión nuclear norcoreana es un conflicto inter-

ción o limitación no está presupuesta en el derecho internacional público. Similar, la Opinión Consultiva de la Corte Internacional de Justicia sobre la legalidad de la amenaza o el empleo de armas nucleares, ICJ Rep. 1996, p. 226, párr. 105.

55. Conformados por el Tratado de Prohibición Parcial de Ensayos Nucleares (TPPEN) de 1963 y el Tratado de Prohibición Completa de Ensayos Nucleares (TPCE) de 1996, este último aún no en vigor.

56. Tratado sobre la Prohibición de Armas Nucleares de 2017 que entra en vigor con la 50. ${ }^{\mathrm{a}}$ ratificación, UN Doc A/Conf.229/2017/8. Prohíbe la producción, posesión, estacionamiento, empleo y la amenaza con armas nucleares; es una prohibición general, sin excepción, de todas las armas nucleares, que implica su eliminación, por tanto es un rechazo de la doctrina de la disuasión nuclear. No complementa al TNP, sino que es su «antídoto»; de ahí se entiende por qué la conferencia que condujo al Tratado fue rechazada y boicoteada por las potencias nucleares, miembros de la OTAN, más Australia y Japón. 
nacional. Mientras esta idea permanezca utópica, se hace necesario revisarlas por lo menos a nivel académico. En esto resaltan sobre todo sus problemas con el principio de proporcionalidad en diversos aspectos.

El primero está en el carácter desmesurado de las sanciones, visto en su dureza, extensión, su poder multiplicador, universalizador, indeterminado, ilimitado y de vida indeterminada. Su dureza se ve sobre todo en el impedimento del goce de los derechos de preservación y defensa, y de la libertad fundamental del Estado norcoreano de ejercer comercio con el exterior y generarse sus propios recursos de subsistencia, lo que está ocasionando daños no estimables a su economía y desarrollo. Su extensión está en el hecho de que las sanciones le impiden prácticamente cualquier interacción económica, financiera, militar, industrial, laboral, cultural y científica con el exterior, lo que cala hasta en su derecho fundamental de cooperación con otros Estados. Su poder multiplicador y universalizador es visible al ser obligatorias para todos los Estados y participar en ellas todos los Estados. Su duración indeterminada hace posible que se extiendan en el tiempo por muchísimas décadas, como parece ser en el caso norcoreano. Su poder ilimitado está visto en la facultad de cada Estado de interpretar y aplicar extensivamente las sanciones de la ONU, e imponer además sanciones unilaterales independientes.

El segundo, en cuanto a sus consecuencias reales, los daños materiales que las sanciones ocasionan al Estado y población norcoreanos - subdesarrollo, pobreza, aislamiento, recortes de la calidad de vida, del bienestar individual y la salud, etcétera- son excesivos con respecto al daño inmaterial de «amenaza a la paz», sobre todo cuando tales actividades nucleares no han ocasionado daño material concreto a Estado o individuo alguno, y tienen un carácter defensivo. No se puede comprender cómo China y Rusia permitieron que las sanciones de la ONU lleguen a tal dureza. Ambos Estados han sido renuentes a ellas; Rusia más claramente las ha calificado de "contraproducentes y peligrosas», y se ha pronunciado contra tal «estrangulación económica». ${ }^{57}$ No se descarta que estos Estados las hicieron pasar bajo la presión internacional de mostrar responsabilidad por el régimen de no proliferación, del que son partes integrantes y tienen en común con las potencias occidentales. El tercero, su instrumentalización como «arma económica y política» al servicio de una de las partes del conflicto nuclear: Estados Unidos y su aliado Corea del Sur, quienes poseen con ellas un instrumento más de presión para obtener de Corea del Norte mayores concesiones en futuras negociaciones de desnuclearización, y han abierto más la brecha en esta relación sumamente desigual. Todas estas reflexiones arrojan el resultado de que estas sanciones no son legítimas y deberán ser revisadas y levantadas por lo menos en parte.

57. Louis Nelson, «Russia's foreign minister warns Tillerson: New North Korea sanctions could be “dangerous"», Politico, 31 de agosto de 2017, disponible en politi.co/3gLpXCh. 


\section{Rol de las sanciones de Naciones Unidas en el conflicto nuclear norcoreano}

A la cuestión de si las sanciones internacionales han sido y son el camino adecuado para solucionar el problema de la nuclearización norcoreana, solo puede responderse teniendo en cuenta el conflicto nuclear norcoreano-estadounidense subyacente en sus aspectos históricos, desde sus orígenes hasta el presente, en el aspecto social, económico, geopolítico y jurídico. Sin pretender llegar a un examen cabal, se anticipa una respuesta negativa.

En cuanto a las sanciones de la ONU, no se puede ver cómo o en qué aspecto concreto del problema de la nuclearización norcoreana han contribuido al restablecimiento de la "paz internacional». Naciones Unidas ha aislado o «arrancado» las «actividades nucleares» de Corea del Norte de su contexto político conflictivo, que es bastante complejo en sí. Asimismo, la «tensión» creada por las actividades nucleares norcoreanas es tan abstracta como el «restablecimiento de la paz», que se puede llegar a la conclusión de que no existió ninguno de los dos, y lo contrario. El restablecimiento de la paz internacional consistía más en llamar la atención a las dos partes a que desistan de actos provocativos mutuos, en abrir un proceso de diálogo sin sanciones, y exhortar a ambas partes a actuar de buena voluntad hacia un tratado de desnuclearización empalmado previamente a un tratado de paz, que incluya la desnuclearización de toda la península de Corea. Ello podría hacerse a partir de acuerdos como el Tratado Marco de 1994 y el del Grupo de las Seis Partes, que Corea del Norte estuvo dispuesta a cumplir y cumplió en parte, esperando que Estados Unidos también haga lo mismo. Se trataba de incitar y exigir la creación de un proceso de paz nivelado y balanceado de concesiones recíprocas; supervisado a la vez por una ONU neutral o un mecanismo multilateral, semejante o igual al Grupo de las Seis Partes, que asegure que en tal relación asimétrica el fuerte no oprima la voluntad del más débil y produzca con ello una situación equivalente a una capitulación sin guerra.

La realidad de las sanciones de la ONU es otra. Ellas juegan el rol de ser un instrumento más en favor de los intereses de Estados Unidos y su aliado Corea del Sur, y con ello les otorga más recursos de presión en perjuicio de los intereses de Corea del Norte. Tienen el efecto entonces de abrir más la brecha de una relación desigual entre Estados que están aún en estado legal de guerra, dándole más recursos al más fuerte y quitándoselos a la parte más débil; con ello albergan el peligro de generar un tratado desigual bajo las mismas condiciones; situación condenada en el derecho internacional público por pisotear principios fundamentales de justicia internacional. Este rol negativo, visto en su instrumentalización hegemónica que contradice demandas de equidad, no aparece recién con las primeras sanciones de la ONU contra Corea del Norte desde 2006, sino ya poco después del nacimiento de esta organización. Ella intervino en el conflicto político de la península moldeando su destino en el sentido de la política estadounidense de la siguiente manera: contribuyó en forma significativa en la partición 
de la península en dos Coreas en 1947, como había sido diseñado por Estados Unidos; intervino militarmente en la guerra de Corea de 1950 al lado de Estados Unidos contra Corea del Norte, y últimamente, ha intervenido otra vez en el conflicto nuclear norcoreano-estadounidense con sanciones contra Corea del Norte; hechos que muestran una vez más el carácter sistémico de su instrumentalización hegemónica.

\section{Conclusión}

Corea del Norte es objeto de dos regímenes de sanciones que corren paralelos e independientes el uno al otro: el régimen de las sanciones colectivas de la ONU y el régimen de sanciones unilaterales, propulsadas ambas por Estados Unidos. Regímenes extensos y complejos, dotados de sus propios mecanismos de ejecución y cumplimiento a nivel universal. En lo concerniente al primero, se ha podido notar que no ha sido efectivo por no haber conseguido que Corea del Norte se retracte de sus actividades y programa nuclear y balístico. A pesar de esta inefectividad, que los hace inservibles en sus objetivos propuestos, ellos siguen en pie y están ocasionando serios daños en la vida económica y en el desarrollo del Estado y pueblo norcoreano. Lo están castigando duramente y creando a la vez el peligro latente de una emergencia humanitaria, por lo que deberá ser revisado pronto.

Mientras las sanciones de la ONU parecen tener una justificación legal, no sin reservas sobre todo en cuanto a la proporcionalidad, es más difícil aceptar su legitimidad por múltiples factores vistos en su estructura política inadecuada, en su falta de garantías para los sancionados, en su instrumentalización sistemática y en su dimensión desproporcional que otra vez conlleva a problemas de proporcionalidad. Este problema de proporcionalidad es reforzado viendo el carácter defensivo y reactivo de los actos de militarización y nuclearización norcoreanos, los que incluso al ser provocativos y de gravedad, responden a iguales actos provocantes de la alianza militar y nuclear estadounidense-surcoreana, que por otro lado no tiene que temer ser objeto de sanciones por estos actos. Tampoco han sido necesarias por haber existido siempre una vía del diálogo entre Estados Unidos y Corea del Norte, y por ser el primero el que se resiste a tratar con el régimen de Pyongyang y negociar con él al nivel que se dio en el Tratado Marco de 1994. Por ello, nuevamente se tiene que volver a las raíces del conflicto nuclear norcoreano-estadounidense para lograr su solución, que no radica en las sanciones, sino en la vía del diálogo hacia una desnuclearización completa de la península de Corea dentro de un proceso de paz serio, sólido y sostenible, y bajo los principios de bona fides, reciprocidad, respeto mutuo y respeto a la situación de diferencia desfavorable de Corea del Norte frente a un poderoso Estados Unidos. En este proceso tendrá que estar incluido el desmantelamiento progresivo de las sanciones internacionales, empresa difícil de emprender en la actual situación política, pero la esperanza es lo último que se pierde. 


\section{Referencias}

Asada, Masahiko (2020). «Definition and legal justification of sanctions». En Masahiko Asada (editor), Economic sanctions in international law and practice. Londres: Routledge.

BIERSTEKER, Thomas (director) (2001). Targeted financial sanctions: A manual for design and implementation. Rhode Island: The Thomas J. Watson Jr. Institute for International Studies.

Bleckmann, Albert (1982). Zur Rechtmäßigkeit der EG-Sanktionen gegen Argentinien nach allegemeinen Völkerrecht und dem Recht der EG, Europa-Institut. Saarbrücken: Universität des Saarlandes 4.

BorLINI, Leonardo S. (2016). «The DPRK's gauntlet, international law and the new sanctions imposed by the Security Council». En XXVI Italian Yearbook of International Law (pp. 319-345). DOI: 10.2139/ssrn.3287418.

Brzoska, Michael (2001). Design and implementation of arms embargoes and travel and aviation related sanctions: Results of the Bonn-Berlin process. Bonn: BICC.

CAMERON, Iain (2005). «Protecting legal rights: On the (in) security of targeted sanctions». En Peter Wallensteen y Carina Staibano (editores), International sanctions: Between words and wars in the global system (pp. 181-206). Londres: Routledge.

СомвасAU, Jean (1986). «Sanctions». En Rudolf Bernhardt y otros (editores), Encyclopedia of Public International Law (EPIL) 9 (pp. 337-341). Amsterdam: North Holland.

Conlon, Paul (1996». Die Rechtliche Problematik von UN-Sanktionen als Mittel zur Durchsetzung des Völkerrechts. Kiel: Universität Kiel.

Cortright, David y George A. López (2002). Smart sanctions: Targeting economic statecraft. Lanham: Rowman \& Littlefield.

Cumings, Bruce (2004). North Korea: Another Country. Nueva York: The New Press.

DeLurY, John (2016). "The disappointments of disengagement: Assessing Obama's North Korea policy». En John Nilsson-Wright (editor), The politics and international relations of modern Korea (pp. 194-217). Oxon: Routledge.

Doxey, Margaret (1971). «The Rhodesian sanctions experiment». The Yearbook of World Affairs, 25: 142-162.

Drezner, Daniel W. (2011). «Sanctions sometimes smart: Targeted sanctions in theory and practice». International Studies Review, 13: 96-108.

FefFer, John (2004). Nordkorea und die USA. Kreuzlingen: Diederichs.

Fu, Ying (2017). «The Korean Nuclear issue: Past, present and future. A Chinese perspective». J. L. Thornton China Center at Brookings Strategy Paper, 3: 1-24.

Gordon, Richard, Michael Smyth y Tom Cornell (editores) (2020). Sanctions law. Londres: Bloomsbury. 
HAFNER, Gerhard (2006). «Völkerrechtliche Grenzen und Wirksamkeit von Sanktionen gegen Völkerrechtssubjekte». ZaöRV, 76: 391-413.

HAPPOLD, Matthew (2016). «Economic sanctions and international law: An introduction». En Matthew Happold y Paul Eden (editores), Economic sanctions and international law (pp. 1-2). Oxford: Hart.

HeriK, Larissa van den (editora) (2017). Research handbook of UN sanctions and international law. Cheltenham: Elgar.

Hufbauer, Gary C., Jeffrey J. Schott, Kimberly Ann Elliott y Barbara Oegg (2007). Economic sanctions Reconsidered. Washington D. C.: PIIE.

JOYNeR, Daniel H. (2017). «UN counter-proliferation sanctions and international law». En Larissa van den Herik (editora), Research handbook of UN sanctions and international law (pp. 105-124). Cheltenham: Elgar.

Kristensen, Hans M. y Matt Korda (2020). «United States nuclear forces». Bulletin of the Atomic Scientists, 76 (1): 46-60. DOI: 10.1080/00963402.2019.1701286.

Kristensen, Hans M. y Robert S. Norris (2017). «A history of US nuclear weapons in South Korea». Bulletin of the Atomic Scientists, 73 (6): 349-357. DOI: 10.1080/00963402.2017.1388656.

LitTLE, Richard (2018). «Foreword». En Mark Daniel Jaeger, Coercive sanctions and international conflicts. Londres: Routledge.

Malanczuk, Peter (1983). «Countermeasures and self-defence as circumstances precluding wrongfulness in the international law commission's draft articles on State responsibility». ZaöRV, 43: 705-812.

Meyer, Frank y Julia Macke (2007). «Rechtliche Auswirkungen der Terrorliste im deutschen Recht». Onlinezeitschrift für Höchstrichterliche Rechtsprechung zum Strafrecht, 12: 445-465.

MüNKLER, Herfried (2006). Imperien. Berlín: Rowohlt.

Pellet, Allain y Alina Miron (2011). «Sanctions». En Max Planck Encyclopedia of Public International Law. Oxford: Oxford University Press.

Portella, Clara (2011). «Impact of sanctions and isolation measurement with North Korea, Burma, Iran and Zimbabwe as case studies». Research Collection School of Social Sciences, 1.685: 11-15. Disponible en bit.ly/3j702tl.

RonZITTI, Natalino (2016). «Sanctions as instruments of coercive diplomacy: An international law perspective». En Natalino Ronzitti (editor), Coercive diplomacy, sanctions and international law. Leiden: Brill Nijhoff.

RuYs, Tom (2017). «Sanctions, retorsions and countermeasures: Concepts and international legal framework». En Larissa van den Herik (editora), Research handbook of UN sanctions and international law (pp. 105-124). Cheltenham: Elgar.

SchlochHauer, Hans-Jürgen y Karl Strupp (1963). Wörterbuch des Völkerrechts. Tomo 3. Berlín: De Gruyter. 
Tostensen, Arne y Beate Bull (2002). «Are smart sanctions feasible?». World Politics, 54 (3): 373-403. Disponible en bit.ly/3zIhIyi.

Wallensteen, Peter, Carina Staibano y Mikael Eriksson (editores) (2003). Making targeted sanctions effective: Guidelines for the implementation of UN policy options department of peace and conflict research. Uppsala: Uppsala University.

YoNG-Joong LeE, Eric (2007). «Legal analysis of the 2006 UN Security Council resolutions against North Korea’s WMD development». Fordham International Law Journal, 31 (1): 1-33. Disponible en bit.ly/3zC5qHr.

\section{Sobre la autora}

María Cecilia Añaños Meza es abogada. LL.M. Kiel, Alemania. Doctora en Derechos Fundamentales, Universidad Carlos III de Madrid. España. investigadora y docente en Derecho Internacional Público. Su correo electrónico es ceciliaan@web. de. (D) https://orcid.org/0000-0001-9892-9704. 
La Revista Tribuna Internacional busca fomentar la reflexión, el debate, el análisis y la comunicación pluralista y con rigor científico en las áreas del derecho internacional público, derecho internacional privado, relaciones internacionales y derecho internacional de los derechos humanos. Los artículos y ensayos son seleccionados mediante revisión de pares externos a la Facultad de Derecho de la Universidad de Chile. Se reciben trabajos en castellano y en inglés.

EDITOR GENERAL

Luis Valentín Ferrada Walker

SITIO WEB

tribunainternacional.uchile.cl

CORREO ELECTRÓNICO

revistatribuna@derecho.uchile.cl

LICENCIA DE ESTE ARTÍ́CULO

Creative Commons Atribución Compartir Igual 4.o Internacional

La edición de textos, el diseño editorial

y la conversión a formatos electrónicos de este artículo

estuvieron a cargo de Tipográfica

(www.tipografica.io) 